\title{
A Theory of Domestic and International Trade
}

Finance

JaeBin Ahn 


\title{
IMF Working Paper
}

\author{
Research Department
}

\section{A Theory of Domestic and International Trade Finance ${ }^{1}$ \\ Prepared by JaeBin Ahn}

\author{
Authorized for distribution by Atish R. Ghosh
}

November 2011

\section{This Working Paper should not be reported as representing the views of the IMF. The views expressed in this Working Paper are those of the author(s) and do not necessarily represent those of the IMF or IMF policy. Working Papers describe research in progress by the author(s) and are published to elicit comments and to further debate.}

\begin{abstract}
This paper provides a theory model of trade finance to explain the "great trade collapse." The model shows that, first, the riskiness of international transactions rises relative to domestic transactions during economic downturns, and second, the exclusive use of a letter of credit in international transactions exacerbates a collapse in trade during a financial crisis. The basic model considers banks' optimal screening decisions in the presence of counterparty default risks. In equilibrium, banks will maintain a higher precision screening test for domestic firms and a lower precision screening test for foreign firms, which constitutes the main mechanism of the model.

JEL Classification Numbers: F1, F4, G2

Keywords: trade finance, great trade collapse, payment system, letter of credit, screening Author's E-Mail Address: jahn@imf.org

\footnotetext{
${ }^{1}$ I am especially grateful to Don Davis, Amit Khandelwal, and David Weinstein for their constant encouragement, and thank to Mariana Colacelli, Alexander McQuoid, Marge Miller, Mika Saito, Yoichi Sugita, Eric Verhoogen, Jon Vogel, Anna Watson, and seminar participants at various institutions for their very helpful comments.
} 


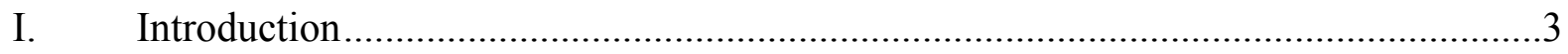

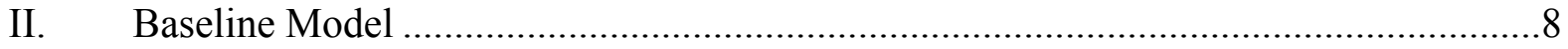

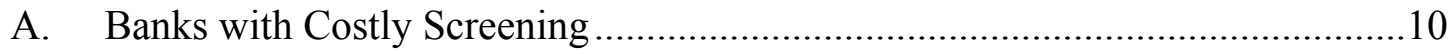

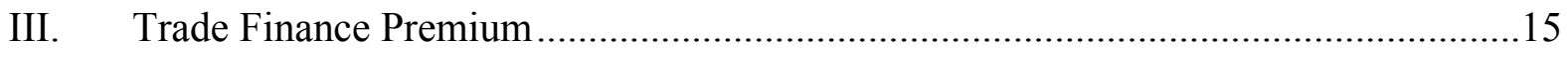

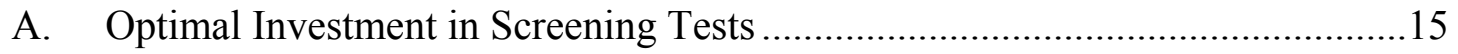

B. Counter-Cyclical Trade Finance Premium ................................................. 18

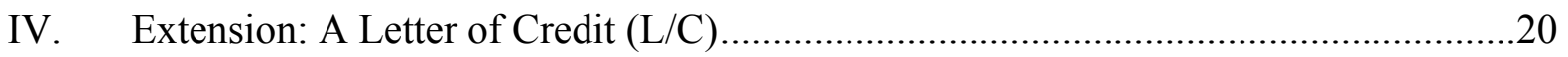

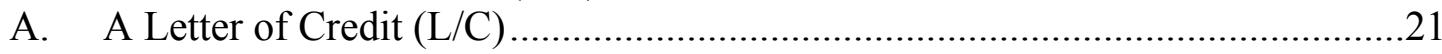

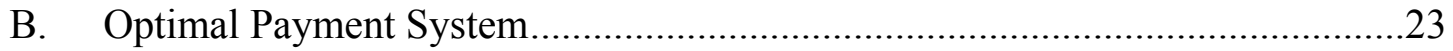

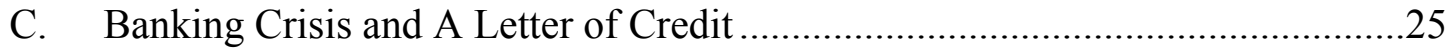

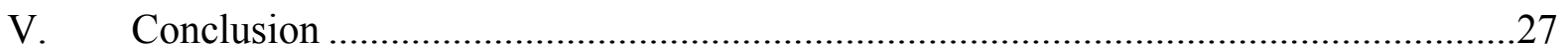

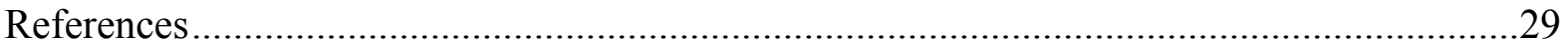

Figures

1. Screening Tests for Transactions Under Open Account System ...............................11

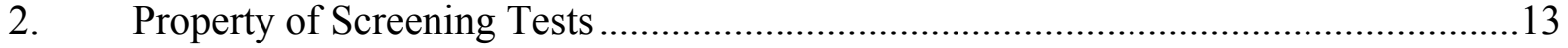

3. Optimal Investment in Screening Tests ........................................................... 17

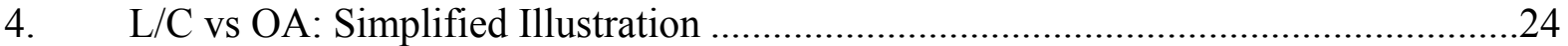

5. Cyclicality of the Relative Export Sales (L/C) to Domestic Sales (OA) ...................26 


\section{Introduction}

Exchange takes time. For example, when a seller receives a purchase order that stipulates payment after delivery, the seller has to produce and ship a product before the buyer pays. This requires financing over short horizons because the seller may need to borrow working capital to complete the order or may purchase credit insurance to protect against counterparty defaults. That is the essence of trade finance. ${ }^{1}$ It is often described as the lifeline of business transactions because more than $90 \%$ of transactions involves some form of credit, insurance or guarantee (International Trade Center, 2009). It was, however, not until the recent financial crisis that trade finance came to the attention of academic researchers.

The financial crisis of 2008-2009 is the most severe world macroeconomic shock since the Great Depression. During the crisis period, the collapse of international trade was much swifter and greater than the decline of GDP: world GDP fell by about 5\%, while world trade contracted by about $30 \%$ (Baldwin, 2009). Similarly, while U.S. GDP in this period contracted by $3.8 \%$, U.S. trade contracted much more sharply, by around $20 \%$ (Levchenko, Lewis, and Tesar, 2010). This "great trade collapse" has led economists to suspect that trade finance had a role. This paper presents the theory model that answers the question, "What is the specific role of trade finance in explaining the great trade collapse?"

There are good reasons for thinking that trade finance may be an important part of the story. Growing evidence suggests that international trade finance experienced severe adverse effects in terms of price as well as availability during the same period. The IMF-BAFT survey reports that approximately $90 \%$ of the banks raised the price of international trade finance facilities at the onset of the great trade collapse (Dorsey, 2009; Asmundson et al., 2011), and in some cases the price of letters of credit jumped from 10 15 basis points to 250 500 basis points above LIBOR (Auboin, 2009). Banks in emerging markets also reported that international trade finance transactions declined by $6 \%$ on average during the period. Behind the evidence lies the hypothesis that international trade finance is more sensitive to economic fluctuation or financial crisis than domestic trade finance (e.g., Chauffour and Farole, 2009).

Price data corroborates this hypothesis. Haddad, Harrison, and Hausman (2010) find that U.S. import prices actually rose in manufactured goods, especially in those sectors highly dependent on external finance. Ahn, Amiti, and Weinstein (2011) report that export price increased by $2.5 \sim 6 \%$ relative to domestic price in European Union countries, Japan and the U.S. These facts are strong evidence that supply side shocks played an important role in the

\footnotetext{
${ }^{1}$ In general, trade finance refers to any type of financing that uses trade credit (i.e., accounts receivable) as collateral. This paper defines international trade finance only as a letter of credit and working capital financing for international transactions, opposed to domestic trade finance defined as working capital financing for domestic transactions. The main result of the model will be readily extended to other types of trade finance facilities (e.g., export credit insurance) by introducing risk averse agents.
} 
great trade collapse.

This view is supported by various empirical studies. For example, Amiti and Weinstein (2011), using the uniquely matched database between Japanese listed firms and their main banks, find that firms contract export-to-domestic sales ratio when their main banks become unhealthier, and such a pattern is stronger for smaller firms, non-multinational firms, and industries that export primarily by sea. Iacovone and Zavacka (2009) provide the historical evidence that exports in financially vulnerable sectors were hit harder during banking crises. For the recent global recession period, Chor and Manova (forthcoming) confirm that trade finance is indeed a critical factor for trade activity by showing that countries experiencing higher growth in inter-bank loan rates tend to decrease exports to the U.S. even more, and this is more pronounced in financially dependent sectors. Firm level studies also report that financially constrained firms had greater adverse impacts on exports during this period (Bricongne, Fontagné, Gaulier, Taglioni, and Vicard, forthcoming; Paravisini, Rappoport, Schnabl, and Wolfenzon, 2011), and U.S. inter-firm trade (i.e., trade with payment default risk) with Asian countries declined more sharply than intra-firm trade (i.e., trade with no payment default risk) during the Asian crisis period (Bernard, Jensen, Redding, and Schott, 2009). ${ }^{2}$

Despite the ample empirical evidence, there is a lack of theoretical foundation for understanding the nature of trade finance. In particular, there is no theoretical model in which the asymmetric structure, domestic versus international, of trade finance has been derived from first principles. That is what the current paper achieves. This paper contributes to the literature by examining how international trade finance reacts differently than domestic trade finance during crisis periods. To answer the question, the paper begins with a more fundamental question of what makes international trade finance different from domestic trade finance, and then shows how such difference leads to the great trade collapse.

Mechanics of the model The mechanics of this paper are very straightforward.

International trade is more costly than domestic trade, hence the volume of international transactions will be smaller than domestic transactions. Firms borrow from local banks. Banks need to gather information about whether loans will be repaid. They need not only worry about the firm they loan to, but also any other firms on whose solvency repayment depends. Banks invest more in learning about firms with which they have a larger volume of transactions, which in turn makes them more knowledgeable about these firms. Since banks are involved in larger transactions with domestic than foreign firms, they will also be more knowledgeable about them. This makes international trade finance loans riskier than domestic finance loans. When a crisis hits, information becomes more important because a crisis raises

${ }^{2}$ In contrast, Behrens, Corcos, and Mion (2010) find no such evidence from Belgian firms. 
uncertainty about firms' performance. Having accumulated less information, banks become disproportionately more uncertain about foreign than domestic firms. This translates to the costs of trade financing, and as a result, the relative price of export to domestic goods will rise, and the volume of international transactions will drop more sharply than the volume of domestic transactions during a crisis. The following describes this mechanism in more detail.

The basic model incorporates payment systems used for business transactions. When payment is made by a buyer after delivery (i.e., open account system), a supplier is exposed to non-payment risk from the buyer. As a result, if the supplier borrowed working capital from a bank, the loan performance depends not only on the supplier's credit risk but also on the buyer's credit risk. Likewise, when a buyer makes advance payment to a supplier (i.e., cash-in-advance system), the buyer is subject to non-delivery risk from the supplier. If a bank provided the advance payment, the loan repayment is contingent on the successful performance of both the supplier and the buyer. From the banks' perspective, therefore, it becomes a serious concern to evaluate such creditworthiness of both borrowers and their trading partners to insure loan repayment.

Banks assess this overall transaction risk through screening tests for the borrower's trading partner as well as the borrower. ${ }^{3}$ By investing in information acquisition, banks can improve the precision levels of screening tests, and hence the loan repayment probability of the transactions that pass the screening tests. The optimal precision levels of screening tests are determined by comparing costs and benefits. When screening tests are domestic or foreign firm specific, marginal gains from improving the screening test for domestic firms is proportional to the volume of domestic transactions, and the same is true for the foreign screening. All else being equal, since costly trade results in a larger volume of domestic transactions than international transactions, banks will maintain a higher precision level of screening test for domestic firms than foreign firms. Accordingly, the screening of foreign firms yields a less accurate outcome than domestic screening, making international transactions a relatively higher risk with lower loan repayment probability. Therefore, costs of financing international transactions will be higher, i.e., trade finance premium.

Moreover, the resulting trade finance premium features a counter-cyclical movement. Although an increase in the default risk during a recession will raise the average default rate of firms that passed either screening test, the default rate will rise relatively more for the less precisely screened foreign firms. This is simply because an inferior foreign screening is more

\footnotetext{
${ }^{3}$ The screening technology adopted in this paper follows closely the ones developed in banking literature. Broecker (1990) introduced this particular form of technology in the context of inter-bank competition in credit markets. Flannery (1996) also modeled an identical type of screening test to show the possibility of loan market failure due to an increase in uncertainty during a financial crisis. Freixas and Holthausen (2004) incorporate the screening test into the inter-bank loan market. Hauswald and Marquez (2003, 2006) use the framework to study banks competition through information acquisition. Unlike them, this paper explores the cyclical property of the screening test and endogenizes its precision level.
} 
sensitive to the changes in the default risk due to a larger share of vulnerable firms among the firms passing the screening test. That is, during a recession, the average default rate for international transactions rises relatively more than the one for domestic transactions, as do the costs of financing international transactions. Once the costs of financing pass through to the final goods price, an elastic demand dictates that a fall in trade will dominate a fall in output through the price channel, generating pro-cyclical export-to-output ratio consistent with empirical patterns. ${ }^{4}$

The asymmetric nature of the screening tests for domestic and foreign firms gives rise to a letter of credit system exclusively for international transactions. ${ }^{5}$ Under a letter of credit system, both a buyer's bank and a supplier's bank participate in the transaction as intermediaries. The buyer's bank promises to pay the supplier's bank on behalf of the buyer as long as the goods are delivered from the supplier, and the supplier's bank guarantees to pay the supplier whether the buyer's bank actually pays or not. From the view of the supplier's bank, this essentially switches the non-payment risk from the buyer to the buyer's bank, and thus can replace an inferior screening test for foreign firms by the supplier's bank with a superior screening test for domestic firms by the buyer's bank. This is the gain from using a letter of credit system for international transactions. At the same time, however, since the supplier's bank has only limited, imperfect information on the credit risk of the buyer's bank, it incurs additional inter-bank informational friction. As long as the gains from a letter of credit outweigh the costs, a letter of credit would be chosen as the optimal payment system for the international transaction. On the other hand, this will not be true for domestic transactions because it only incurs additional costs without any gains.

The inter-bank dimension inherent in a letter of credit system provides another channel that adversely affects international trade during a recession or financial crisis. An increase in the bank default risk worsens the informational friction between banks, leading to a higher price charged on a letter of credit. Since the model shows that a letter of credit can be used only for international transactions, such an additional adverse effect is thus unique to international transactions. To sum up, the price channel effect and the letters of credit effect lead to a great decline in international trade than in domestic sales.

Related literature The "great trade collapse" has been the motivation for a variety of theoretical and empirical exercises seeking to account for the much more dramatic collapse in

\footnotetext{
${ }^{4}$ The excess sensitivity of trade relative to domestic output has long been a well-established phenomenon (Engel and Wang, 2011). Most recently, Freund (2009) documents the historical evidence that trade is more responsive to GDP during global downturns.

${ }^{5}$ According to the Society for Worldwide Interbank Financial Telecommunication (SWIFT), nearly $90 \%$ of letters of credit transactions are cross-border transactions (ICC, 2010).
} 
trade relative to GDP. Apart from the trade finance channel studied in this paper, it has been shown that product composition effects (Levchenko et al., 2010), inventory adjustment (Alessandria, Kaboski, and Midrigan, 2010), vertical integration effects (Bems, Johnson, and Yi, 2010), and other demand factors (Eaton, Kortum, Neiman, and Romalis, 2011) played important roles.

This paper contributes to the trade credit literature by providing a novel explanation on the use of letters of credit system for international trade. ${ }^{6}$ In this aspect, this paper is closely related to a growing literature that considers the pattern of an optimal payment system for international trade (Schmidt-Eisenlohr, 2009; Olsen, 2010; Antràs and Foley, 2011). Schmidt-Eisenlohr (2009) shows that firms in a country with relatively lower financing costs or weaker enforcement of contracts offer trade credit to counterpart firms in a country with relatively higher financing costs or stronger enforcement of contracts. Olsen (2010) considers the optimal payment system in the presence of imperfect contract enforcement, and shows how bank intermediation mitigates such problems in international trade. Antràs and Foley (2011) also offer a prediction on the pattern of an optimal payment system based on an imperfect contract approach, and test the prediction using the unique international transactions data from a single U.S. food exporter. Unlike these papers, the current paper endogenizes the relative riskiness of international transactions, and derives the macroeconomic implications from its cyclical property. Another critical difference lies in the mechanism of the model. The asymmetric level of information approach, characterized by differing precision levels of banks' screening tests, is strongly supported by the evidence that the U.S. inter-state banking deregulation increased the volume of inter-state trade (Michlaski and Ors, forthcoming), and the evidence that international banks' cross-border lending declined more sharply for difficult-to-screen borrowers during the recent financial crisis period (De Haas and Van Horen, 2011).

This paper is also related to the literature that studies credit constraints and international trade. In the presence of fixed costs for exporting, credit constrained firms find it difficult to finance such fixed costs, and are discouraged from participating in exporting (Chaney, 2005). This can alter the patterns of trade, depending on industry level financial vulnerability as well as the financial development of the countries (Manova, 2008), and thus financial development can become a source of comparative advantage (Kletzer and Bardhan, 1987; Ju and Wei, 2011). Empirical studies find that financial development leads to a greater level of exports in manufactured goods (Beck, 2002), and credit constrained firms are less likely to become

\footnotetext{
${ }^{6}$ The literature has various views on what determines the use of trade credit (i.e., open account system): transaction costs motive (Ferris, 1981), suppliers' informational advantage on buyers (Biais and Gollier, 1997; Smith, 1987) or better ability in monitoring buyers' moral hazard (Burkart and Ellingsen, 2004)). For further reference, please refer to the references in Petersen and Rajan (1997).
} 
exporters (Mûuls, 2008). ${ }^{7}$ Although the literature focuses on the comparison between non-exporting and exporting firms in terms of long-term fixed costs financing, the current paper studies the difference between short-term domestic and export financing even for a single exporter.

The remainder of the paper proceeds as follows: Section 2 introduces the basic setup of the model. Section 3 describes a bank's optimal investment decision in the precision level of each screening test, proves the existence of trade finance premium, and analyzes its cyclical property. Section 4 extends the analysis to a letter of credit system, and Section 5 concludes.

\section{Baseline Model}

This section introduces a highly stylized version of the model developed in Ahn (2011), in order to deliver the main mechanisms and contributions of the model as efficiently as possible. ${ }^{8}$ This is a story of a single intermediate goods producer (supplier) that supplies intermediate inputs to both domestic and foreign final goods producers (buyers). Intermediate goods are produced with a unit working capital requirement technology, meaning that one unit of working capital (with unit cost $w$ ) is required to produce one unit of intermediate goods. The supplier has the exclusive right to provide the inputs to the corresponding buyers such that the supplier sets the price for intermediate goods from his/her own profit maximization problem. Depending on the geographic location of buyers, it becomes either domestic $(D)$ or international $(F)$ transaction. International transactions incur variable trade costs that take the form of an iceberg-type cost $\left(\tau_{F}>1\right)$, whereas domestic transactions are free of such trade costs $\left(\tau_{D}=1\right)$. This reflects various sources of possible trade costs associated with international transactions, e.g., transportation costs, time costs or tariff rates. ${ }^{9}$ Henceforth, we

\footnotetext{
${ }^{7}$ Greenaway, Guariglia, and Kneller (2007) find that the strong correlation between firms' financial health and exporting status rather comes from the reverse causality, i.e., exporting improves firms' financial health.

${ }^{8}$ A more general version of the model in Ahn (2011) features, among others, firm heterogeneity in the degree of collaterallizable assets to generate differing borrowing costs across firms. The heterogeneity helps the model to replicate the presence of multiple types of payment systems in an economy because this serves as the factor that determines the optimal payment system for each transaction. The resulting predictions on the optimal payment system are consistent with empirical findings that financially constrained firms tend to receive more credit and offer less credit (Petersen and Rajan, 1997; Love, Preve, and Sarria-Allende, 2007).

${ }^{9}$ Essentially, this can be more generalized to capture any other exogenous factors that makes international transactions more costly. For example, weaker contract enforcement across borders considered in SchmidtEisenlohr (2009), Olsen (2010), and Antràs and Foley (2011) can be collapsed into $\tau_{F}$. It is straightforward that adding country specific enforcement level to the current model will provide additional testable prediction across country that are consistent with evidence in Schmidt-Eisenlohr (2009) and Antràs and Foley (2011). Similarly, allowing market size to differ across country will yield richer empirical predictions, leaving the key idea of this paper untouched.
} 
will focus on two different transactions of the intermediate goods producer with, otherwise identical, a domestic and a foreign buyer, respectively.

A novel feature of the model is to consider the payment system for each transaction explicitly. This essentially creates the trade finance channel through which financial factors affect real transactions, and more importantly, domestic and international transactions differentially. In the real world, there are three main modes of payment system: open account (OA), cash-in-advance (CA), and a letter of credit (L/C). The baseline model will assume that every transaction takes place only under the open account system in which suppliers extend credit to buyers such that the intermediate goods are produced and shipped to buyers first and the payment is made later. ${ }^{10}$ We further suppose that a supplier needs to borrow from a bank the entire working capital to produce the goods, and then repay the bank once the payment is made by a buyer. This implies that a supplier can repay the loan only if the payment is made successfully by a buyer.

We consider a final goods producer who transforms a unit of intermediate goods into final goods without any additional cost. Accordingly, the demand for intermediate inputs $\left(q^{s}\right)$ follows exactly the demand for final goods $\left(q^{b}\right)$ in each transaction $i$, which is given as:

$$
q_{i}=q_{i}^{b}=q_{i}^{s}=Q\left(p_{i}^{b}\right)^{-\sigma}
$$

where $Q$ is aggregate market demand level common to every transaction, ${ }^{11} \sigma$ is the price elasticity of demand, and $p_{i}^{b}$ is the final goods price. A final goods producer takes the intermediate goods price, $p_{i}^{s}$, as given, and set the optimal price as markup over marginal cost:

$$
p_{i}^{b}=\frac{1}{\rho} p_{i}^{s}
$$

where $1 / \rho=\sigma /(\sigma-1)$ denotes a constant markup. Similarly, a supplier's optimization problem is characterized as:

$$
\max _{p_{i}^{s}}\left[p_{i}^{s} q_{i}-q_{i} \tau_{i} w r_{i}\right]
$$

to set the price of the intermediate inputs as markup over marginal cost:

\footnotetext{
${ }^{10}$ We defer our discussion on the letter of credit to section 4. As for the cash-in-advance system, it is exactly the mirror image of the open account system in that the payment by buyers is made to suppliers prior to the production or delivery of the intermediate goods. For further details, please refer to Ahn (2011).

${ }^{11}$ The common aggregate market demand level assumption essentially shuts down demand channel effects and leave trade financing as a sole factor that operates in the model.
} 


$$
p_{i}^{s}=\frac{\tau_{i} w}{\rho} r_{i}
$$

where $r_{i}$ is the transaction-specific borrowing cost. It is important to note that a bank charges a transaction-specific interest rate for each loan instead of a borrower-specific interest rate. ${ }^{12}$ This is consistent with real world trade financing practice that short-term financing uses trade credit from each transaction as collateral. Also, firms often sell trade credit to third parties (i.e., factoring), and get a transaction-specific discount which corresponds to the borrowing cost in our model. ${ }^{13}$ In this sense, a bank in the model captures the roles of both a lender and a factor. To determine the transaction-specific borrowing cost $r_{i}$, we now turn to a bank's optimization problem.

\section{A. Banks with Costly Screening Technology}

The banking industry is assumed to be imperfectly competitive due to spatial differentiation: each bank is designated as a main bank for borrowers in the region. ${ }^{14}$ Whenever a bank makes a lending decision to support a transaction (i.e., trade finance lending decision), it needs to evaluate the associated failure risk of the transaction that arises from either the buyer (i.e., borrower's trading partner) or the supplier (i.e, borrower); a supplier may default and fail to produce the intermediate goods or a buyer may default and fail to make a payment to the supplier.

Specifically, we assume that there are two types of firms: good firms $(\Theta=G)$ with a fraction $\mu_{G} \geq 1 / 2$ and bad firms $(\Theta=B)$ with a fraction $\left(1-\mu_{G}\right) \leq 1 / 2 .{ }^{15}$ A good firm never defaults (default probability $=0$ ), while a bad firm defaults with probability $0<\lambda<1 .{ }^{16}$ The information on a firm's type is unknown to a bank. To distinguish good firms from bad firms, banks use a screening test. The precision level of the test depends on the amount of information on firms that banks have acquired. The information is firm specific such that the

\footnotetext{
${ }^{12}$ On the contrary, Feenstra, Li, and Yu (2011) consider the case in which a bank cannot verify whether the loan is used to cover the costs of production for domestic sales or for exports. Also, we rule out the possibility of cross-pledging by which one transaction serves as collateral for the other transaction.

${ }^{13}$ Factoring helps a seller transfer a buyer's non-payment risk to a factor. In return for the assumed risk, a factoring company charges discount to a seller, which is based on the buyer's creditworthiness.

${ }^{14}$ Modeling endogenous banking competition is beyond the scope of this paper. There is an extensive literature on this issue including Dell'Ariccia (2001) and Champonnois (2009) among others.

${ }^{15}$ This is common to both suppliers and buyers: $\mu_{G}=\mu_{G, s}=\mu_{G, b}$

${ }^{16}$ Hence, $\lambda\left(1-\mu_{G}\right)$ is the economy wide default rate. This may include both voluntary and involuntary default but the distinction is not relevant in the current model.
} 
precision level of screening test for a borrower, borrower's domestic trading partner, and its foreign trading partner is denoted as $\alpha_{C}, \alpha_{D}, \alpha_{F}$, respectively. ${ }^{17}$ Instead of assuming exogenously given precision levels, we will consider information acquisition as a costly investment such that banks optimally choose the amount of information, and hence the precision level of screening test, for each group (to be discussed in Section 3 below). The screening system for a trade finance lending described above is illustrated in (Figure 1).

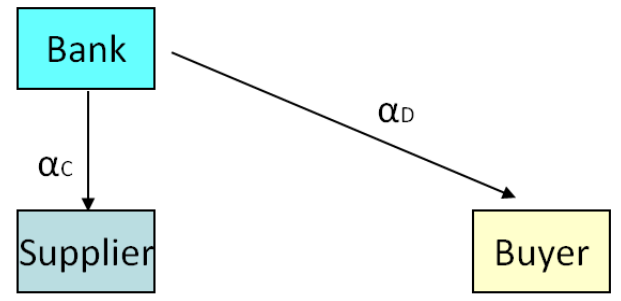

domestic transactions

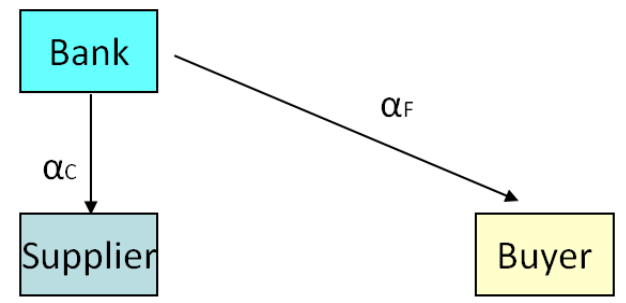

international transactions

Figure 1: Screening Tests for Transactions Under Open Account System

Regarding the precision level of screening tests $\alpha_{j}$, it is defined as the probability of receiving a good signal $(S=G)$ conditional on firms' being good, and symmetrically for bad signals:

Definition 1 The precision level of screening is defined as

$$
\left.\alpha_{j} \equiv \operatorname{prob}\left(S_{j}=G \text { । } \Theta_{j}=G\right)=\operatorname{prob}\left(S_{j}=B\right) \text { । } \Theta_{j}=B\right)
$$

for $j=C, D, F$ and $1 / 2 \leq \alpha_{j} \leq 1$.

Accordingly, the probability of receiving a good signal is:

$$
\gamma_{j} \equiv \operatorname{prob}\left(S_{j}=G\right)=\overbrace{\mu_{G} \alpha_{j}}^{\Theta_{j}=G}+\overbrace{\left(1-\mu_{G}\right)\left(1-\alpha_{j}\right)}^{\Theta_{j}=B}
$$

When a screening technology is imperfect $\left(\alpha_{j}<1\right)$, banks can receive good signals from bad firms as well as good firms. This implies that the probability of firms not defaulting,

\footnotetext{
${ }^{17}$ In short, under the open account system, the supplier's bank screens the supplier with the precision level $\alpha_{C}$, and the domestic buyer with the precision level $\alpha_{D}$, but screens the foreign buyer with the precision level $\alpha_{F}$.
} 
conditional on observing a good signal can then be expressed as ${ }^{18}$ :

$$
\chi_{G}^{j} \equiv \frac{\mu_{G} \alpha_{j}+\left(1-\mu_{G}\right)\left(1-\alpha_{j}\right)(1-\lambda)}{\gamma_{j}}
$$

As long as a screening test is informative $(\alpha>1 / 2)$, a firm with a good signal is less likely to default than a firm with a bad signal $\left(\chi_{G}^{j}>\chi_{B}^{j}\right)$ and, throughout the paper, we will assume that a screening is precise enough to ensure that there are too few good firms with a bad signal for a bank to make a profit from lending to this group ${ }^{19}$ :

Assumption 1 (Credit Rationing) Whenever either party of the transaction receives a bad signal, banks deny a loan for the transaction.

Lemma $1 \chi_{G}^{j}$ is an (i) increasing and (ii) weakly concave function of the precision level $\alpha_{j}$ :

$$
\begin{aligned}
\frac{\partial \chi_{G}^{j}}{\partial \alpha_{j}} & =\frac{\lambda\left(1-\mu_{G}\right) \mu_{G}}{\left[\mu_{G} \alpha_{j}+\left(1-\mu_{G}\right)\left(1-\alpha_{j}\right)\right]^{2}}>0 \\
\frac{\partial^{2} \chi_{G}^{j}}{\partial \alpha_{j}^{2}} & =\frac{-2\left(2 \mu_{G}-1\right)}{\left[\mu_{G} \alpha_{j}+\left(1-\mu_{G}\right)\left(1-\alpha_{j}\right)\right]^{3}} \leq 0
\end{aligned}
$$

Lemma 2 The elasticity of $\chi_{G}^{j}$ with respect to $\lambda$ is (i) negative and (ii) increasing in the precision level $\alpha_{j}$ :

$$
\begin{gathered}
\frac{\partial \ln \chi_{G}^{j}}{\partial \ln \lambda}=\frac{-2 \lambda\left(1-\mu_{G}\right)\left(1-\alpha_{j}\right)}{\left[\mu_{G} \alpha_{j}+\left(1-\mu_{G}\right)\left(1-\alpha_{j}\right)(1-\lambda)\right]}<0 \\
\frac{\partial}{\partial \alpha_{j}}\left(\frac{\partial \ln \chi_{G}^{j}}{\partial \ln \lambda}\right)=\frac{\lambda \mu_{G}\left(1-\mu_{G}\right)\left(2-\alpha_{j}\right)}{\left[\mu_{G} \alpha_{j}+\left(1-\mu_{G}\right)\left(1-\alpha_{j}\right)(1-\lambda)\right]^{2}}>0
\end{gathered}
$$

\footnotetext{
${ }^{18}$ Similarly, the probability of firms not defaulting, conditional on observing a bad signal is: $\chi_{B}^{j} \equiv$ $\frac{\mu_{G}\left(1-\alpha_{j}\right)+\left(1-\mu_{G}\right)\left(\alpha_{j}\right)(1-\lambda)}{\left(1-\gamma_{j}\right)}$

${ }^{19}$ In fact, we can introduce fixed costs for production explicitly and derive this as a result of the model rather than an assumption. Footnote 22 discusses the condition for this assumption in detail.
} 
The property of screening tests is summarized in Lemma 1 and 2 above and illustrated in (Figure 2).

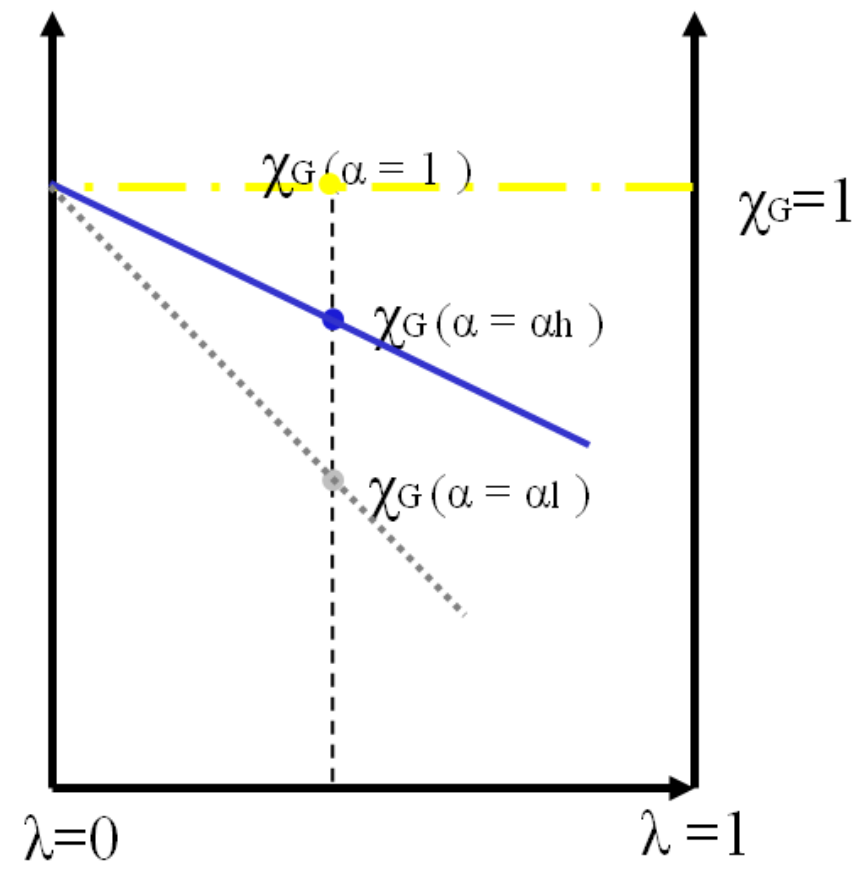

Figure 2: Property of Screening Tests

Equation (7) in Lemma 1 implies that a higher precision screening test yields better loan performance, i.e., $\chi_{G}^{j}$ curve with a higher precision level $\alpha_{h}$ (solid line) lies above the curve with a lower precision level $\alpha_{l}$ (dotted line), where $\alpha_{l}<\alpha_{h}<1$. When a screening is perfect, no bad firms can receive a good signal, and thus, $\chi_{G}^{j}=1$ (dashed line). Equation (9) in Lemma 2 shows that an imperfect screening test yields better loan performance as the economy wide default rate $(\lambda)$ decreases, and vice versa, i.e., $\chi_{G}^{j}$ curve is decreasing in $\lambda$. According to equation (10) in Lemma 2, this tendency is stronger as a screening test is less precise, i.e., $\chi_{G}^{j}$ curve with a higher precision level $\alpha_{h}$ (solid curve) is less steep than the curve with a lower precision level $\alpha_{l}$ (dotted curve). For example, as $\lambda$ approaches 0 , there is no firm default in the economy, and thus the loan repayment probability for both high and low precision test converges to 1 . On the contrary, the loan performance gap between tests widens as $\lambda$ increases. This is simply because a low precision screening test, relative to a high precision screening, is more likely to include bad firms in the bank's loan portfolio, and hence is more sensitive to changes in $\lambda$.

Having described screening tests for each trade finance lending, we now turn to a bank's optimization problem. A bank lends working capital $\left(q_{i} \tau_{i} w\right)$ to a supplier and gets gross 
repayment $\left(q_{i} \tau_{i} w r_{i}\right)$ only if neither supplier nor buyer defaults during the transaction cycle. Otherwise, the bank ends up with non-performing loan. Whenever a bank receives a bad signal from either a supplier or a buyer, it refuses to lend, and the transaction is not viable (Assumption 1). This amounts to the loan repayment probability of $\chi_{G}^{C} \chi_{G}^{i}$ for each transaction $i$ because the transaction is financed only when both parties receive good signals (with probability $\gamma_{C} \gamma_{i}$ ), where now $i=D$ for domestic transaction and $F$ for international transaction. ${ }^{20}$ The bank's expected profit maximization is then, with costs of fund normalized as 1, :

$$
\max _{r_{i}}\left[\chi_{G}^{C} \chi_{G}^{i} q_{i} \tau_{i} w r_{i}-q_{i} \tau_{i} w\right]
$$

and the optimal interest rate charged to a supplier for a transaction $i$ is solved as: ${ }^{21}$

$$
r_{i}=\frac{1}{\rho} \frac{1}{\chi_{G}^{C} \chi_{G}^{i}}
$$

It is intuitive that the borrowing cost is decreasing in the success probability of the transaction $\left(\partial r_{i} / \partial \chi_{G}^{D} \chi_{G}^{j}<0\right){ }^{22}$ The interest rates charged on domestic trade finance loan and international trade finance loan differs due only to the different precision level of screening tests for domestic and foreign buyer. This, in turn, affects relative price of export to domestic intermediated goods because the borrowing cost in equation (12) enters the intermediate goods price in equation (4):

$$
p_{i}^{s}=\frac{1}{\rho^{2}} \frac{\tau_{i} w}{\chi_{G}^{C} \chi_{G}^{i}},
$$

generating the complete pass-through of the borrowing cost into the intermediate goods price. Inserting this into equation (2) gives the final goods price:

\footnotetext{
${ }^{20} \mathrm{~A}$ bank lends to local domestic suppliers only and the corresponding buyers could be either domestic or foreign. This implies that the screening test used for suppliers has the precision level $\alpha_{C}$, while the one for buyers is $\alpha_{j}$ for $j=D, F$.

${ }^{21}$ Equations (2) and (4) are combined to enter equation (1). In short, the bank takes into account the effect of the lending rate on final good demand.

${ }^{22}$ This is the rationale for Assumption 1. Bad signaled transactions (i.e., the supplier-buyer pairs in which at least one party receives a bad signal) face higher borrowing costs than good signaled transactions (i.e., the supplier-buyer pairs in which none receives a bad signal) due to a lower probability of loan repayment. This means that bad signaled transactions generate lower revenue, and hence lower profits due to a higher final goods price and elastic demand. We can introduce the fixed cost such that the bad signaled transactions end up with negative profits, and hence full repayment cannot occur. Knowing this is going to happen, a bank will not provide a loan for such transactions. The corresponding fixed cost that satisfies the condition lies in the range between $B\left[1 /\left(\chi_{G}^{C} \chi_{B}^{F}\right)\right]^{1-\sigma}$ and $B\left[1 /\left(\chi_{G}^{C} \chi_{G}^{F}\right)\right]^{1-\sigma}$, where $B=Q(1-\rho) \rho^{3 \sigma-2}\left(\tau_{F} w\right)^{1-\sigma}$.
} 


$$
p_{i}^{b}=\frac{1}{\rho^{3}} \frac{\tau_{i} w}{\chi_{G}^{C} \chi_{G}^{i}}
$$

Now, we are ready to study how optimal precision levels of domestic and foreign screening tests (i.e., $\alpha_{D}$ and $\alpha_{F}$ ) are determined.

\section{Trade Finance Premium}

\section{A. Optimal Investment in Screening Tests}

So far, we have treated the different precision levels of screening tests $\alpha_{j}$ as exogenous parameters. In this section, we consider a bank's optimal precision level of screening tests on each firm. As described earlier, banks can improve the precision level of each screening test by acquiring the information on each firm (i.e., borrower, domestic and foreign buyers). When it is costly to acquire the information, banks will optimally choose the precision level by considering the marginal gains and marginal costs of the information acquisition. Intuitively, banks will continue investing in the information acquisition until the marginal gains from additional information are no greater than the marginal costs. A possible discrepancy in marginal gains across firms will generate different precision levels of screening tests even when we assume an identical cost function for domestic and foreign information acquisition.

Marginal costs curve We assume that the information is firm specific (i.e., borrower, domestic and foreign firms), costly to obtain, and the marginal costs of the information acquisition are increasing with the precision level (and hence increasing in the amount of information obtained). This assumption implies that it is more difficult or expensive to improve the screening test as it gets closer to being perfect. Formally, we impose the following assumption on the information acquisition cost function $C(\alpha)$, and one example of marginal cost functions that satisfies the following assumption is a linear curve featured in (Figure 3). ${ }^{23}$

Assumption 2 (i) $C(\alpha)>0$, (ii) $C^{\prime}(\alpha)>0$, (iii) $C^{\prime}(\alpha=1 / 2)=0$, and (iv) $C^{\prime \prime}(\alpha)>0$

\footnotetext{
${ }^{23}$ It is plausible to assume that marginal costs of acquiring local firms information is lower than marginal costs of acquiring foreign firms information, which will strengthen the results of this paper. However, this assumption is not made throughout the paper in order to highlight the endogenous nature of asymmetric screening tests.
} 
Marginal gains curve A bank earns profits from financing domestic and international transactions:

$$
\pi_{\text {bank }}=\pi_{\text {bank }}^{D}+\pi_{\text {bank }}^{F}
$$

As described in (Figure 1), a domestic screening test is used to evaluate the creditworthiness of the borrowers' domestic trading partners, whereas a foreign screening test is applied to the borrowers' foreign trading partners. When a bank improves the precision level of the foreign screening test, the bank can assess the credit risks of the borrowers' foreign trading partners more accurately, and thus will expect to earn greater profits from an international trade financing business:

$$
\frac{\partial \pi_{b a n k}}{\partial \alpha_{F}}=\frac{\partial \pi_{b a n k}^{F}}{\partial \alpha_{F}}
$$

On the other hand, improving the domestic screening test raises the bank's profits from a domestic trade financing business:

$$
\frac{\partial \pi_{\text {bank }}}{\partial \alpha_{D}}=\frac{\partial \pi_{\text {bank }}^{D}}{\partial \alpha_{D}}
$$

because it allows the banks to screen the borrowers' domestic trading partner more precisely.

Using the bank's optimization problem in equation (11), combined with equation (12) and (14), we can express the bank's profits from each trade finance lending as:

$$
\pi_{\text {bank }}^{i}=A \tau_{i}^{1-\sigma}\left(\chi_{G}^{C} \chi_{G}^{i}\right)^{\sigma}
$$

where $A=\frac{1}{\sigma-1} Q \rho^{2 \sigma} w^{1-\sigma}$ and $i=D, F$. Differentiating the bank's profits from each line of business with respect to $\alpha$ gives corresponding marginal gains function:

$$
\frac{\partial \pi_{b a n k}^{D}}{\partial \alpha_{D}}=\frac{\partial \pi_{b a n k}^{D}}{\partial \chi_{G}^{D}} \cdot \frac{\partial \chi_{G}^{D}}{\partial \alpha_{D}}=\sigma A\left(\chi_{G}^{C}\right)^{\sigma}\left(\chi_{G}^{D}\right)^{\sigma-1} \cdot \frac{\partial \chi_{G}^{D}}{\partial \alpha_{D}},
$$

for domestic screening test improvement and:

$$
\frac{\partial \pi_{b a n k}^{F}}{\partial \alpha_{F}}=\frac{\partial \pi_{b a n k}^{F}}{\partial \chi_{G}^{F}} \cdot \frac{\partial \chi_{G}^{F}}{\partial \alpha_{F}}=\tau_{F}^{1-\sigma} \sigma A\left(\chi_{G}^{C}\right)^{\sigma}\left(\chi_{G}^{F}\right)^{\sigma-1} \cdot \frac{\partial \chi_{G}^{F}}{\partial \alpha_{F}},
$$

for foreign screening test improvement. For every level of $\alpha_{D}=\alpha_{F}$ (hence $\chi_{G}^{D}=\chi_{G}^{F}$ ) with a given $\alpha_{C}$, equation (16) and (17) are identical except for the additional term $\tau_{F}^{1-\sigma}<1$ in equation (17). In the presence of trade costs, all else being equal, the volume of domestic 
transactions is greater than the volume of international transactions. Since marginal gains from improving each screening test are proportional to the volume of transactions affected by that specific screening test, marginal gains from improving the domestic screening test are always greater than marginal gains from improving the foreign screening test. Consequently, as shown in (Figure 3), the marginal gains curve for domestic screening improvement always lies above the one for foreign screening improvement, and therefore, the optimal precision level is determined at a higher level for the domestic screening test than the foreign screening test. $^{24}$ This establishes $\alpha_{F}^{*}<\alpha_{D}^{*}$ in equilibrium.

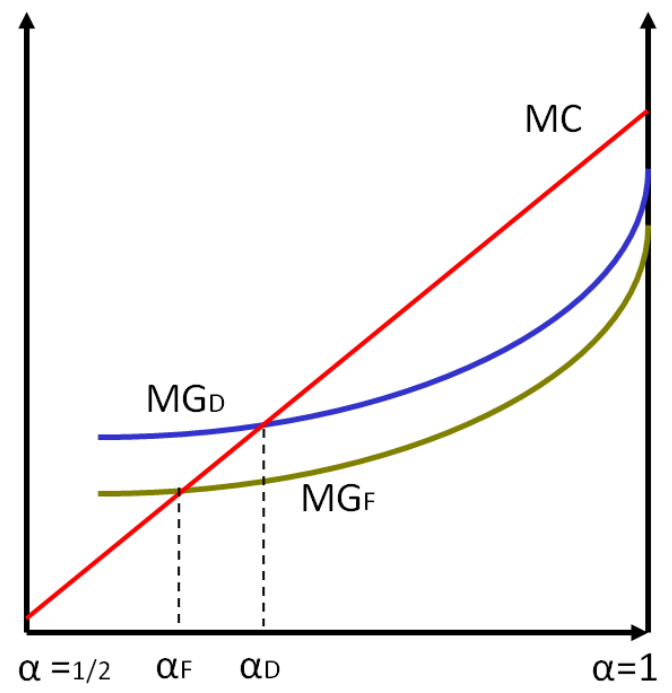

Figure 3: Optimal Investment in Screening Tests

Proposition 1 In equilibrium, the screening test for domestic firms has a higher precision level than the one for foreign firms $\left(\alpha_{F}^{*}<\alpha_{D}^{*}\right)$.

A direct consequence of Proposition 1 is that international transactions are subject to higher default risks than domestic transactions because the screening test for foreign firms is more likely to misclassify bad firms as good. This results in higher borrowing costs for international transactions. More specifically, since the borrowing cost is decreasing in the loan repayment probability $\chi_{G}^{C} \chi_{G}^{j}$, and $\chi_{G}^{F}<\chi_{G}^{D}$ from Proposition 1, it follows from equation (12) that $r^{F} / r^{D}>1$, which we will call the trade finance premium. Furthermore, the borrowing cost

\footnotetext{
${ }^{24}$ In this figure, marginal gains curves are drawn as upward sloping. This is always true when $\mu_{G}=1 / 2$. Otherwise, it is ambiguous whether the curves are upward or downward sloping, but this does not affect the following Proposition.
} 
completely passes through to the final goods price, which leads to $p_{F} / p_{D}>\tau_{F}$ : reinforcing the home market bias due to trade costs. This completes the proof of the following Corollary.

Corollary 1 There exists a trade finance premium, $r^{F} / r^{D}>1$, reflecting riskier international transactions than domestic transactions. This is completely passed-through to the final goods price, and reinforces the home market bias.

Noting that improving the borrower screening test benefits from both domestic and international trade finance loans, the marginal gains from improving the borrower screening test are greater than the marginal gains from improving the domestic or foreign screening test. Combined with an increasing marginal cost curve, this leads to a relatively higher precision level for the borrower screening test than the domestic or foreign screening test.

Proposition 2 In equilibrium, the screening test for borrowers has the highest precision level $\left(\alpha_{F}^{*}<\alpha_{D}^{*}<\alpha_{C}^{*}\right)$.

Proof. In the appendix.

\section{B. Counter-Cyclical Trade Finance Premium}

Next, we turn to the cyclical property of a trade finance premium. The default rate of firms fluctuates over a business cycle, i.e., default rates are higher in recessions than in booms. This section performs a simple comparative static analysis by changing the default probability of firms in the economy, $\lambda .{ }^{25}$ We take the precision level of screening tests as predetermined, and examine the sole effect of a change in $\lambda$ on the trade finance premium and export-to-domestic sales ratio. The implicit assumption here is that in the very short run, banks cannot quickly update or adjust their information on firms. Therefore, they apply screening tests based on the information acquired earlier. This is best understood as short run fluctuations around the steady state.

From Assumption 1, only the good signaled transactions get financed by banks. The probability of receiving good signals on borrowers and their counterparts is $\gamma_{C}$ and $\gamma_{j}$ respectively. Among them, $\chi_{G}^{C}$ fraction of the good signaled borrowers and $\chi_{G}^{j}$ fraction of the good signaled counterparts operates successfully. Therefore, the actual volume of successful transactions is expressed as:

\footnotetext{
${ }^{25}$ Alternatively, we can think of a decrease in the share of good firms $\left(\mu_{G}\right)$ during the recession. This gives qualitatively identical results.
} 


$$
V^{j}=\gamma_{C} \gamma_{j} \chi_{G}^{C} \chi_{G}^{j} \cdot q_{j}=\gamma_{C} \gamma_{j} \chi_{G}^{C} \chi_{G}^{j} \cdot A\left[p_{j}^{b}\right]^{-\sigma}
$$

for $j=D, F$.

It then follows that the relative volume of successful international transactions to domestic transactions is:

$$
\begin{aligned}
V^{F, D} & =\frac{V^{F}}{V^{D}}=\frac{\beta_{F}}{\beta_{D}} \cdot\left[\frac{p_{F}^{b}}{p_{D}^{b}}\right]^{-\sigma} \\
& =\overbrace{\frac{\beta_{F}}{\beta_{D}}}^{\text {probability effect }} \cdot \overbrace{\left[\tau_{F} \frac{r_{F}}{r_{D}}\right]^{-\sigma}}^{\text {price effect }},
\end{aligned}
$$

where $\beta_{j}=\mu_{G} \alpha_{j}+\left(1-\mu_{G}\right)\left(1-\alpha_{j}\right)(1-\lambda)$.

There are two terms that determine the relative volume of export-to-domestic sales. The probability effect term represents the relative success probability of international transactions to domestic transactions. Since the counterparts screening is less precise for international transactions from Proposition 1, international transactions are more likely to include bad firms that are subject to default, leading to a lower probability of successful international transactions relative to domestic transactions: $\beta_{F} / \beta_{D}<1$. A direct interpretation of this result is already discussed in Corollary 1 , that international transactions are riskier than domestic transactions, and thus there exists a trade finance premium. This is captured by the price effect term.

Moreover, a change in the default rate $\lambda$ will affect both terms in equation (19), and their movements will govern the cyclical property of the export-to-domestic sales ratio. As $\lambda$ increases during a recession, the probability of successful transactions decreases for both international and domestic transactions. In particular, Lemma 2 predicts that this tendency is stronger for international transactions because they are more likely to include bad firms that are directly affected by an increase in the default rate $\lambda$. This implies that the relative riskiness of international transactions increases during a recession, and the opposite is also true during a boom. This in turn implies that the trade finance premium increases as $\lambda$ increases (i.e., counter-cyclical trade finance premium). Therefore, we conclude that both probability and price effect generate a pro-cyclical export-to-domestic sales ratio.

Proposition 3 The export-to-domestic sales ratio is pro-cyclical in that it decreases as $\lambda$ increases, and increases as $\lambda$ decreases via both probability effect and price effect. This is the direct consequence of the counter-cyclical relative riskiness of international transactions. 
Proof. In the appendix.

The counter-cyclical movement in the relative price is consistent with the evidence reported in Ahn et al. (2011) that export price increased relative to domestic price in Japan, the U.S., and European Union countries during the recent crisis. This also explains the finding in Haddad et al. (2010) that U.S. import prices rose in financially vulnerable sectors. This price effect would lead to a decline in the export-to-domestic sales ratio along the intensive margin, which was the predominant channel in the collapse in trade (Bricongne et al., 2010; Paravisini et al., 2010).

\section{Extension: A Letter of Credit (L/C)}

In this section, we extend the baseline model to consider the letter of credit system, and we will show why letters of credit are used only for international transactions, and how this amplifies the pro-cyclicality of export-to-domestic sales ratio. In the real world, letters of credit are used exclusively for international transactions, and they involve a buyer's bank and a supplier's bank in such a way that the former guarantees the payment to the latter on behalf of buyers. For this reason, the supplier's bank is now free from the buyer's default risk. Instead, by accepting the agreement, the supplier's bank is obliged to pay the supplier whether the buyer's bank actually pays or not. ${ }^{26}$ Since the buyer's bank is also subject to default risk (with $1 / 2 \leq \mu_{\text {bank }}<1$ and $0<\lambda_{\text {bank }}<1$ ), the supplier's bank needs to evaluate the creditworthiness of the counterpart bank prior to accepting the letters of credit procedure. We make the following assumptions regarding the inter-bank screening test: ${ }^{27}$

Assumption 1' A letter of credit issued by a buyer's bank is denied by a suppliers' bank if a bad signal on the buyer's bank is received.

Assumption 3 The precision level of inter-bank screening is exogenously given as $\bar{\alpha}_{\text {bank }}<1$.

\footnotetext{
${ }^{26}$ This corresponds to the irrevocable confirmed letters of credit. Detailed descriptions on various kinds of letters of credit can be found, for example, in Venedikian and Warfield (2000).

${ }^{27}$ Instead of introducing Assumption 3, we could have the precision level of inter-bank screening $\bar{\alpha}_{\text {bank }}$ as an endogenous variable as we did for firms screening. We do not pursue this path because it complicates the model without adding much insights. Also, we do not consider the possibility that inter-bank screening for foreign banks might differ from the one for domestic banks. Although the exactly same logic of the current model can be applied to the inter-bank screening, the underlying assumption is that discrepancy in the domestic and international interbank screening is negligible in magnitude relative to firms screening due to substantially higher volume (and more frequent) of financial transactions between banks.
} 


\section{A. A Letter of Credit (L/C)}

Buyer's Problem By issuing a letter of credit, a buyer's bank obligates itself to pay a supplier's bank on behalf of a buyer, as long as the intermediate goods are shipped. From the bank's perspective, the letter of credit issuance essentially amounts to providing a loan to the buyer because the reimbursement is made to the buyer's bank only if the buyer and the supplier operate successfully in the market (with probability $\chi_{G}^{C} \chi_{G}^{C}$ ). ${ }^{28}$ The cost function for a buyer is expressed as $p_{s} q r$, and taking the interest rate as a given, the buyer maximizes the expected profit function:

$$
\max _{p_{b}} \chi_{G}^{C} \chi_{G}^{C}\left[p_{b} q-p_{s} q r_{b}\right]
$$

that yields the optimal final goods price:

$$
p_{b}=\frac{1}{\rho} p_{s} r_{b}
$$

Issuing Bank's Problem (Buyer's Bank) Once the agreement to use a letter of credit is made (with probability $\gamma_{C} \gamma_{C} \gamma_{\text {bank }}$ ) and the intermediate goods are shipped (with probability $\chi_{G}^{C}$ ), the buyer's bank has to meet the obligation to pay the supplier's bank. ${ }^{29}$ Unless the buyer defaults, the bank receives the repayment at the gross interest rate $r_{b}$ (i.e, a letter of credit fee). The expected profit of the buyer's bank is then:

$$
\max _{r_{b}} \chi_{G}^{C} p_{s} q r_{b}-p_{s} q
$$

and the corresponding optimal interest rate (a letter of credit fee) is:

$$
r_{b}=\frac{1}{\rho}\left[\frac{1}{\chi_{G}^{C}}\right]
$$

The buyer's cost of using a letter of credit decreases as the reimbursement probability increases.

\footnotetext{
${ }^{28}$ Note that a buyer's screening is done by the buyer's local bank with borrower screening precision level $\left(\alpha_{C}\right)$, while a supplier's screening is done by the supplier's local bank with borrower screening precision level $\left(\alpha_{C}\right)$.

${ }^{29}$ For a letter of credit to be used for a transaction, it is necessary that a buyer passes a screening test by the buyer's local bank (with probability $\gamma_{C}$ ), and a supplier and the buyer's bank pass screening tests by the supplier's local bank (with probability $\gamma_{C} \gamma_{\text {bank }}$ ).
} 
Supplier's Problem The supplier's bank is guaranteed to receive the payment from the buyer's bank on behalf of the buyer, but at the same time promises to pay the supplier whether the buyer's bank actually pays or not. Since the supplier receives the payment only after the successful production and delivery of the inputs (with probability $\chi_{G}^{C}$ ), the supplier still faces the working capital financing problem. A supplier borrows the total working capital from the bank at the interest rate $r_{s}$, and thus the cost function for the supplier is $q \tau_{j} w r_{s}$. With the letter of credit discount rate $\delta$ charged by the supplier's bank, the supplier's expected profit function becomes:

$$
\max _{p_{s}} \chi_{G}^{C}\left[(1-\delta) p_{s} q-q \tau_{j} w r_{s}\right]
$$

and the optimal input price is set as:

$$
p_{s}=\frac{\tau_{j} w}{\rho} \frac{r_{s}}{(1-\delta)}
$$

Confirming Bank's Problem (Supplier's Bank) The supplier's bank would receive the payment from the buyer's bank only if the buyer's bank does not default (with probability $\chi_{G}^{b a n k}$, while the guaranteed payment with discounts is made to the supplier irrespective of the buyer's bank default, as long as the intermediate goods are shipped without any problem (with probability $\chi_{G}^{C}$ ). The supplier completes the process by repaying the gross working capital loan. This is summarized in the following expected profit maximization problem:

$$
\max _{\delta, r_{s}} \chi_{G}^{C}\left[\chi_{G}^{b a n k} p_{s} q-(1-\delta) p_{s} q+q \tau_{j} w r_{s}\right]-q \tau_{j} w
$$

Note that there are two choice variables for the supplier's bank: the discount rate $\delta$ for the letter of credit, and interest rate $r_{s}$ for working capital loan. Solving the first order condition with regard to the discount rate, we get:

$$
\frac{1}{1-\delta}=\frac{1}{\chi_{G}^{C} \chi_{G}^{b a n k} r_{s}}+\frac{1}{\sigma-1} \frac{1}{\chi_{G}^{b a n k}}
$$

as a function of $r_{s}$ and other model parameters. This equation provides the set of combinations $\left(\delta, r_{s}\right)$ that maximizes the bank's profit. Any pair of $\left(\delta, r_{s}\right)$ that satisfies the equation (25) can be chosen by the profit maximizing bank. Without loss of generality, we will focus on one particular pair in order to simplify the mathematical expressions:

$$
r_{s}=\frac{1}{\chi_{G}^{C}} \Leftrightarrow \frac{1}{1-\delta}=\frac{1}{\rho} \frac{1}{\chi_{G}^{b a n k}}
$$


The supplier's bank charges the discount rate for letters of credit that is solely up to the counterpart bank's default risk, and the supplier faces borrowing costs depending on its default risk. Substituting the supplier bank's optimal discount and interest rate from equation (26) into equation (23), we get the input price:

$$
p_{s}=\frac{\tau_{j} w}{\rho^{2}}\left[\frac{1}{\chi_{G}^{b a n k} \chi_{G}^{C}}\right]
$$

which, in turn, enters equation (20) together with equation (22) to yield the final good price:

$$
p_{b}^{L / C}=\frac{\tau_{j} w}{\rho^{4}}\left[\frac{1}{\chi_{G}^{b a n k} \chi_{G}^{C} \chi_{G}^{C}}\right]
$$

\section{B. Optimal Payment System}

In actual business transactions, we observe the letter of credit system being used exclusively for international transactions. In our model framework, this will be true if the expected profit from the letter of credit system is always smaller than the expected profit from open account system for domestic transactions, but not necessarily for international transactions.

We present the issue in a formal way by comparing the expected profits from each payment system explicitly below. We assume that a buyer has the bargaining power to choose the optimal payment system for a transaction, and compare the buyer's expected profits from a letter of credit system ${ }^{30}$

$$
\pi_{b}^{j, L / C}=\chi_{G}^{C} \chi_{G}^{C} \chi_{G}^{b a n k}\left[A(1-\rho)\left(p_{b}^{j, L / C}\right)^{1-\sigma}\right]
$$

to the buyer's expected profit from an open account system:

$$
\pi_{b}^{j, O A}=\chi_{G}^{C} \chi_{G}^{j}\left[A(1-\rho)\left(p_{b}^{j, O A}\right)^{1-\sigma}\right],
$$

for $j=D, F$. Taking the ratio between the two, we obtain the condition:

$$
\left(\rho \chi_{G}^{b a n k}\right)^{\sigma-1} \leq\left(\frac{\chi_{G}^{j}}{\chi_{G}^{C}}\right)^{\sigma}
$$

\footnotetext{
${ }^{30}$ The case in which the supplier has the bargaining power to choose the optimal payment system delivers qualitatively similar results.
} 
under which an open account system is always preferred to a letter of credit system. Therefore, we conclude that:

Proposition 4 When $\bar{\alpha}_{\text {bank }}$ is set such that the condition $\left(\chi_{G}^{F} / \chi_{G}^{C}\right)^{\sigma} \leq\left(\rho \chi_{G}^{b a n k}\right)^{\sigma-1} \leq\left(\chi_{G}^{D} / \chi_{G}^{C}\right)^{\sigma}$ is satisfied, a letter of credit is used for international transaction only.

The condition given in the above Proposition makes it clear that a letter of credit is more likely to be chosen as the quality gap between borrowers and their trading partners screening widens (i.e., gains from using a letter of credit increase) for a given level of inter-bank informational friction (i.e., costs of using a letter of credit). The former is captured in the term $\chi_{G}^{j} / \chi_{G}^{C}$, while the latter is given as $\chi_{G}^{b a n k}$. The incentive for using a letter of credit comes from the asymmetric nature of screening tests for borrowers and their trading partners. Since borrower screening is always superior to others, as shown in Corollary 2, passing along the task of screening borrowers' trading partners to their own banks will reduce the overall credit risk of the transaction. However, using a letter of credit incurs additional costs involved in the screening procedure of the counterpart bank, due to inter-bank informational friction. The gains from a letter of credit will exceed the costs of using it if there is a large quality difference in borrowers and their trading partners screening relative to the size of inter-bank informational friction. The larger quality difference in borrowers and their foreign trading partners screening tests means that there are larger gains from using a letter of credit for international transaction (i.e., $\chi_{G}^{F} / \chi_{G}^{C} \ll 1$ ), whereas the smaller quality difference in borrowers and their domestic trading partner leads to smaller gains from using a letter of credit system (i.e., $\chi_{G}^{D} / \chi_{G}^{C} \approx 1$ ). This is illustrated in (Figure 4).

(a) L/C vs OA in domestic transactions

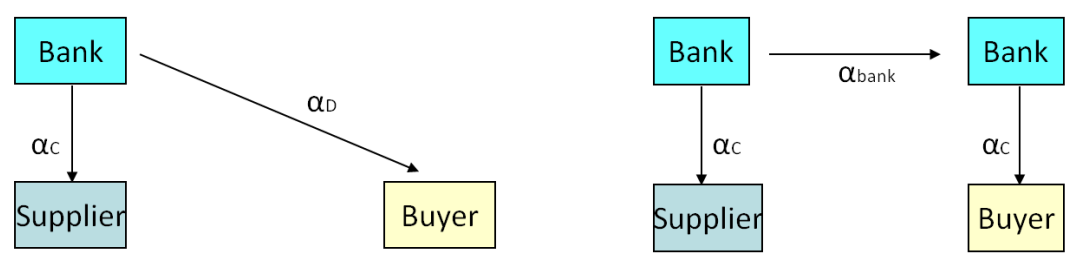

(b) L/C vs OA in international transactions

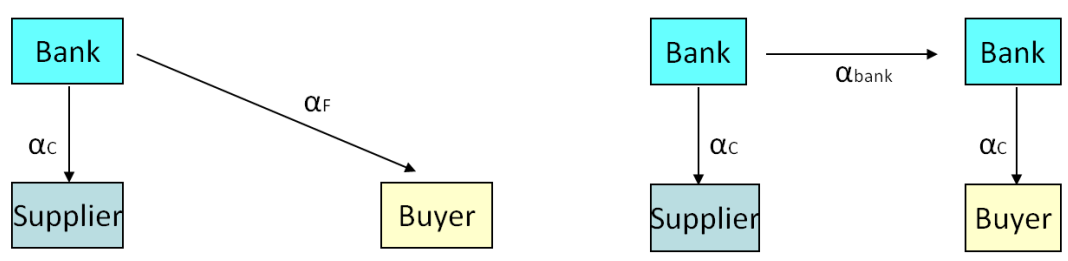

Figure 4: L/C vs OA: Simplified Illustration 


\section{Banking Crisis and A Letter of Credit}

We repeat the comparative statics by changing the firms and banks default rates $\lambda$ and $\lambda_{\text {bank }}$ to study their impacts on the export-to-domestic sales ratio, but now assuming that a letter of credit is optimally chosen for international transactions, and domestic transactions use an open account system. Again, we will focus only on the short run response wherein the optimal level of information is predetermined.

From Assumption 1', only good signaled banks are approved for issuing a letter of credit on behalf of buyers, and this occurs with probability $\gamma_{b a n k}$. Buyers and suppliers receive good signals from screening tests with probability $\gamma_{C}$, and $\chi_{G}^{C}$ fraction of them operate successfully. Therefore, the actual volume of successful international transactions under the letter of credit system is:

$$
\begin{aligned}
V^{F, L / C} & =\gamma_{C} \gamma_{C} \gamma_{b a n k} \chi_{G}^{C} \chi_{G}^{C} \cdot q^{F, L / C} \\
& =\gamma_{C} \gamma_{C} \gamma_{b a n k} \chi_{G}^{C} \chi_{G}^{C} \cdot A\left[p_{b}^{F, L / C}\right]^{-\sigma}
\end{aligned}
$$

The volume of domestic transactions undertaken by an open account is expressed in equation (18), and thus the relative volume of export-to-domestic sales is:

$$
\begin{aligned}
V^{F, D, L / C} & =\frac{V^{F, L / C}}{V^{D, O A}}=\frac{\gamma_{C}}{\gamma_{D}} \gamma_{b a n k} \cdot \frac{\chi_{G}^{C}}{\chi_{G}^{D}} \cdot\left(\frac{p^{F, L / C}}{p^{D, O A}}\right)^{-\sigma} \\
& =C \cdot\left(\frac{\chi_{G}^{C}}{\chi_{G}^{D}}\right)^{1+\sigma}\left(\chi_{G}^{b a n k}\right)^{\sigma}
\end{aligned}
$$

where $C=\frac{\gamma_{C}}{\gamma_{D}} \gamma_{b a n k} \rho^{\sigma}$. Since the changes in the default rate have no effect on $C$ (i.e, $\partial C / \partial \lambda=0)$, the cyclical property of the relative volume of export-to-domestic sales depends only on the movements in $\chi$ terms:

$$
d \ln V^{F, L / C}=(1+\sigma)(\overbrace{\frac{d \ln \chi_{G}^{C}}{d \ln \lambda}-\frac{d \ln \chi_{G}^{D}}{d \ln \lambda}}^{I>0}) d \ln \lambda+\sigma(\overbrace{\frac{d \ln \chi_{G}^{\text {bank }}}{d \ln \lambda_{\text {bank }}}}^{I I<0}) d \ln \lambda_{\text {bank }}
$$

As an economy goes under and default rates increase, the potential risk of the loans will also increase (i.e., $d \ln \chi_{G}^{j} / d \ln \left(\lambda, \lambda_{\text {bank }}\right)<0$ ), the degree of which depends on the relative precision level of screening tests. From Lemma 2, the term $I$ is positive, while the term $I I$ is negative. Depending on which term outweighs the other, the export-to-domestic sales ratio 
could be either counter-cyclical (i.e., $d \ln V^{F, L / C} / d \ln \left(\lambda, \lambda_{\text {bank }}\right)>0$ ) or pro-cyclical (i.e., $\left.d \ln V^{F, L / C} / d \ln \left(\lambda, \lambda_{b a n k}\right)<0\right)$. Despite its ambiguity in general, the condition (28) given in Proposition 4 allows us to determine the cyclicality of the export-to-domestic sales ratio. Note that the term $I$ attains the maximum level when $\chi_{G}^{D}$ takes the lowest possible value satisfying the condition in (28). This corresponds to:

$$
\left(\rho \chi_{G}^{b a n k}\right)^{(\sigma-1) / \sigma} \chi_{G}^{C}=\chi_{G}^{D},
$$

leading to the relative volume of export-to domestic sales:

$$
V^{F, D, L / C}=C^{\prime} \cdot\left(\chi_{G}^{b a n k}\right)^{1 / \sigma},
$$

where $C^{\prime}=C \rho^{(\sigma-1)(\sigma+1) / \sigma}$. Accordingly, equation (30) that characterizes the cyclicality of the relative volume of export-to-domestic sales is rewritten as:

$$
\frac{d \ln V^{F, L / C}}{d \ln \lambda_{b a n k}}=\frac{1}{\sigma}\left(\frac{d \ln \chi_{G}^{b a n k}}{d \ln \lambda_{b a n k}}\right)<0,
$$

Since the elasticity of export-to-domestic sales ratio in equation (32) is the maximum level satisfying the condition in (28), we can conclude that the export-to-domestic sales ratio is pro-cyclical.

L/C in international transactions

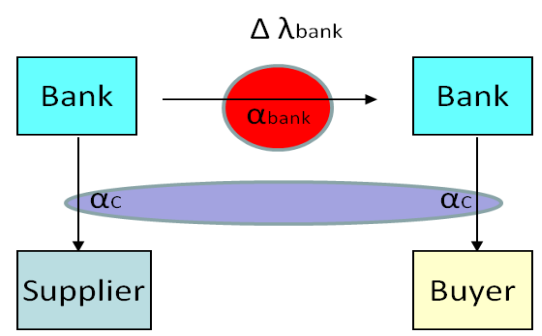

OA in domestic transactions

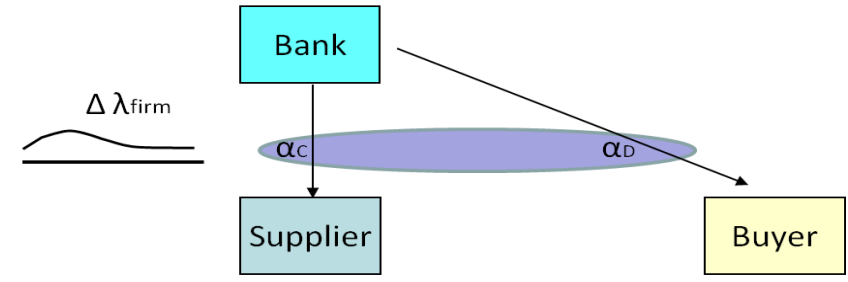

Figure 5: Cyclicality of the Relative Export Sales (L/C) to Domestic Sales (OA)

(Figure 5) gives an intuitive explanation on the cyclicality of the export-to-domestic sales ratio in this case. For an international transaction using a letter of credit, inter-bank screening is performed with the precision level $\bar{\alpha}_{\text {bank }}$ and borrowers screening with $\alpha_{C}$; the latter applies for a borrower screening of a domestic transaction under an open account as well, while the borrower's domestic trading partner is screened with the precision level $\alpha_{D}$. As the firms default rate increases, the potential risks of a buyer and a supplier increases but at the similar 
rate for an international transaction using a letter of credit and a domestic transaction under an open account due to the similar precision level of screening tests. However, the inter-bank dimension unique in the letter of credit system provides the channel through which the changes in the banks default rate drives an increase in the price of the goods exported using a letter of credit without any impact on the domestic goods. This results in a counter-cyclical relative price, and hence a pro-cyclical movement in the export-to-domestic sales ratio. This movement will be proportional to the changes in the banks default rate, and therefore a banking crisis with a surge in the banks default rate is expected to accompany a drop in the export-to-domestic sales ratio as we saw during the recent trade collapse.

Proposition 5 Exports using a letter of credit decline faster than open account domestic sales during recessions, and the opposite is true during booms. This is due to the inter-bank dimension unique in the letter of credit system, which is expected to be much more severe when a recession is accompanied by a banking crisis.

Since a letter of credit is used only for international transactions from Proposition 4, this effect exacerbates a collapse in trade. This particular channel would be economically significant as U.S. Bankruptcy Court document shows that substantial share of unsecured claims to Lehman Brothers was provided by letters of credit. ${ }^{31}$ Indeed, the inter-bank dimension in the letter of credit system resembles the one in the inter-bank loan market. A banking crisis raises uncertainty about the counterparty default risk, which results in soaring inter-bank loan rates (Afonso, Kovner, and Schoar, forthcoming; Heider, Hoerova, and Holthausen, 2010). Similarly, an increase in the counterparty default risk raises the price of a letter of credit (IMF-BAFT, 2009).

\section{Conclusion}

This paper presents a unique framework that explains the different nature of international relative to domestic trade finance. In particular, the current paper explains why international trade finance loans are riskier than domestic trade finance loans, and why a letter of credit is used exclusively for international trade. The model considers banks' optimal screening decision in the presence of counterparty default risks. In equilibrium, banks will maintain a higher precision screening test for domestic firms and a lower precision screening test for foreign firms, which gives rise to the different nature of domestic and international trade finance. The model can explain the role of trade finance in the recent great trade collapse

\footnotetext{
31 "Amended Schedules of Assets and Liabilities for Lehman Brothers Holdings INC. CASE NO. 08-13555 (JMP)" by United States Bankruptcy Court Southern District of New York.
} 
based on two results: first, the relative riskiness of international transactions to domestic transactions increases during economic downturns, and second, the exclusive use of a letter of credit in international transactions exacerbates the great trade collapse especially when a recession is triggered by a banking crisis.

Extensions of the model developed in this paper could be used to explore other interesting issues. The cyclical property of the screening tests is useful for the inter-bank loan market literature. The onset of the Lehman bankruptcy brought about soaring inter-bank loan rates (Afonso et al., forthcoming). The current mechanism, which predicts soaring lending rates during a financial crisis, would be complementary to existing theory models based on Knightian uncertainty (Pritsker, 2010) or liquidity hoarding in the presence of adverse selection (Heider et al., 2010). Also, a direct extension of the model suggests the unique role of foreign banks in developing countries. Foreign banks will have a comparative advantage in evaluating the creditworthiness of the firms in their home countries, and thus will specialize in international trade finance business. Foreign lending supply shocks are, therefore, expected to have larger adverse impacts on trade than domestic activity. This will be an interesting agenda for future study. 


\section{References}

Afonso, Gara, Anna Kovner, and Antoinette Schoar, (forthcoming), "Stressed, not Frozen:

The Federal Funds Market in the Financial Crisis", Journal of Finance.

Ahn, JaeBin, (2011), "A Theory of Domestic and International Trade Finance," mimeo, available at https://sites.google.com/site/jaebinahn/research

Ahn, JaeBin, Mary Amiti, and David Weinstein, (2011), "Trade Finance and the Great Trade Collapse", American Economic Review Papers and Proceedings, 101(3), 298-302.

Alessandria, George, Joe Kaboski, and Virgiliu Midrigan, (2010), "The Great Trade Collapse of 2008-09: An Inventory Adjustment?," IMF Economic Review, 58(2), 254-294.

Amiti, Mary and David Weinstein, (2011), "Exports and Financial Shocks", Quarterly Journal of Economics, 126(4).

Antràs, Pol and Fritz Foley, (2011), "Poultry in Motion: A Study of International Trade Finance Practices", NBER Working Paper 17091.

Asmundson, Irena, Thomas Dorsey, Armine Khachatryan, Ioana Niculcea, and Mika Saito, (2011), "Trade and Trade Finance in the 2008-09 Financial Crisis", IMF Working Paper $11 / 16$

Auboin, Marc, (2009), "Restoring Trade Finance During a Period of Financial Crisis: Stock-Taking of Recent Initiatives," WTO Staff Working Paper.

Baldwin, Richard, (2009), "The Great Trade Collapse: What Caused It and What Does It Mean?" in Richard Baldwin (eds.), The Great Trade Collapse: Causes, Consequences and Prospects, A VoxEU.org Publication.

Beck, Thorsten, (2002), "Financial Development and International Trade: Is There a Link?," Journal of International Economics, 57(1), 107-131.

Behrens, Kristian, Gregory Corcos, and Giordano Mion, (2010), "Trade Crisis? What Trade Crisis?," CEPR Working Paper 7956.

Bems, Rudolfs, Robert Johnson, and Kei-Mu Yi, (2010), "Demand Spillovers and the Collapse of Trade in the Global Recession", IMF Economic Review, 58(2), 295-326.

Bernard, Andrew, Bradford Jensen, Stephen Redding, and Peter Schott, (2009), "The Margins of U.S. Trade," American Economic Review, 99(2), 487-93.

Biais, Bruno and Christian Gollier, (1997), "Trade Credit and Credit Rationing," Review of 
Financial Studies, 10(4), 903-37.

Bricongne, Jean-Charles, Lionel Fontagné, Guillaume Gaulier, Daria Taglioni, and Vincent Vicard, (forthcoming), "Firms and the Global Crisis: French Exports in the Turmoil," Journal of International Economics.

Broecker, Thorsten, (1990), "Credit-Worthiness Tests and Interbank Competition," Econometrica, 58(2), 429-452.

Burkart, Mike and Tore Ellingsen, (2004), "In-Kind Finance: A Theory of Trade Credit," American Economic Review, 94(3), 569-590.

Champonnois, Sylvain, (2009), "Bank Competition and Economic Stability: the Role of Monetary Policy," mimeo UCSD.

Chauffour, Jean-Pierre and Thomas Farole, (2009), "Trade Finance in Crisis Market Adjustment or Market Failure?," World Bank Working Paper 5003.

Chaney, Thomas, (2005), "Liquidity Constrained Exporters," mimeo University of Chicago.

Chor, Davin and Kalina Manova, (forthcoming), "Off the Click and Back? Credit Conditions and International Trade during the Global Financial Crisis," Journal of International Economics.

De Haas, Ralph and Neeltje Van Horen, (2011), "Running for the Exit: International Banks and Crisis Transmission," European Bank for Reconstruction and Development Working Paper.

Dell'Ariccia, Giovanni, (2001), "Asymmetric Information and the Structure of the Banking Industry," European Economic Review, 45(10), 1957-80.

Dorsey, Thomas, (2009), "Trade Finance Stumbles," Finance and Development, 46(1).

Eaton, Jonathan, Samuel Kortum, Brent Neimann, John Romalis, (2011), "Trade and the Global Recession," NBER Working Paper 16666.

Ferris, Stephen, (1981), "A Transaction Theory of Trade Credit Use," Quarterly Journal of Economics 96 (2), 243-270.

Engel, Charles and Jian Wang, (2011), "International Trade in Durable Goods: Understanding Volatility, Comovement, and Elasticities," Journal of International Economics, 83(1), 37-52.

Feenstra, Robert, Zhiyuan Li, and Miaojie Yu, (2011), "Exports and Credit Constraints 
Under Incomplete Information: Theory and Evidence from China," NBER Working Paper 16940.

Flannery, Mark, (1996), "Financial Crises, Payment System Problems, and Discount Window Lending," Journal of Money, Credit and Banking, 28(4), 804-824.

Freixas, Xavier and Cornelia Holthausen, (2004), "Interbank Market Integration under Asymmetric Information," Review of Financial Studies, 18(2), 459-490.

Freund, Caroline, (2009), “The Trade Response to Global Downturns,” World Bank Working Paper 5015.

Greenaway, David, Alessandra Guariglia, and Richard Kneller, (2007), "Financial Factors and Exporting Decisions," Journal of International Economics 73(2), 377-395.

Haddad, Mona, Ann Harrison, and Catherine Hausman, (2010), "Decomposing the Great Trade Collapse: Products, Prices, and Quantities in the 2008-2009 Crisis," NBER Working Paper 16253.

Hauswald, Robert and Robert Marquez, (2003), "Information Technology and Financial Services Competition," Review of Financial Studies, 16(3), 921-48.

Hauswald, Robert and Robert Marquez, (2006), "Competition and Strategic Information Acquisition in Credit Markets," Review of Financial Studies, 19(3), 967-1000.

Heider, Florian, Marie Hoerova, and Cornelia Holthausen, (2010), "Liquidity Hoarding and Interbank Market Spreads: The Role of Counterparty Risk," European Central Bank Working Paper.

Iacovone, Leonardo, and Veronika Zavacka, (2009), "Banking Crises and Exports: Lessons from the Past," World Bank Working Paper 5016.

International Chamber of Commerce, (2010), "Rethinking Trade Finance."

International Trade Center, (2009), "How to Access Trade Finance: A Guide for Export SMEs."

IMF- BAFT, (2009), "A Survey Among Banks Assessing the Current Trade Finance Environment."

Ju, Jiandong and Shang-Jin Wei. (2011), "When Is Quality of Financial System a Source of Comparative Advantage?." Journal of International Economics, 84(2), 178-187.

Kletzer, Kenneth, and Pranab Bardhan, (1987), "Credit Markets and Patterns of International 
Trade," Journal of Development Economics 27(1-2), 57-70.

Levchenko, Andrei, Logan Lewis, Linda Tesar, (2010), "The Collapse of International Trade during the 2008-2009 Crisis: In Search of the Smoking Gun," IMF Economic Review, 58(2), 214-253.

Love, Inessa, Lorenzo Preve, and Virginia Sarria-Allende. (2007), "Trade Credit and Financial Crises," Journal of Financial Economics. 83(2).

Manova, Kalina, (2008), "Credit Constraints, Heterogenous Firms, and International Trade," NBER Working Paper 14531.

Michalski, Tomasz and Evren Ors, (forthcoming), "(Inter-state) Banking and (Inter-state) Trade: Does Real Integration Follow Financial Integration?," Journal of Financial Economics

Muûls, Mirabelle, (2008), "Exporters and Credit Constraints. A Firm Level Approach," London School of Economics Working Paper.

Myers, Steward and Nicholas Majluf, (1984), "Corporate Financing and Investment Decisions When Firms Have Information That Investors Do Not Have," Journal of Financial Economics, 13(2), 187- 221.

Olsen, Morten, (2010), "Banks in International Trade: Incomplete International Contract Enforcement and Reputation," mimeo, Harvard University.

Paravisini, Daniel, Veronica Rappoport, Philipp Schnabl, and Daniel Wolfenzon, (2011), "Credit Shocks and the Margins of Trade: Evidence from Matche Credit-Export Data," NBER Working Paper 16975.

Peek, Joe, Eric Rosengren, and Geoffrey Tootel, (2003), "Identifying the Macroeconomic Effect of Loan Supply Shocks," Journal of Money, Credit, and Banking, 35(6), 931-46.

Petersen, Mitchell and Raghuram Rajan, (1997), "Trade Credit: Theories and Evidence," Review of Financial Studies, 10(3), 661-691.

Pritsker, Matthew, (2010), "Knightian Uncertainty and Interbank Lending," mimeo Federal Reserve Board.

Schmidt-Eisenlohr, Tim, (2009), "Towards a Theory of Trade Finance," European University Institute Working Paper.

Smith, Janet, (1987), "Trade Credit and Informational Asymmetry," Journal of Finance, 42(4), 863-72. 
Venedikian Harry and Gerald Warfield, (2000), "Global Trade Financing," John Wiley \& Sons, New York. 


\section{Appendix}

Proposition 2 In equilibrium, the screening test for borrowers has the highest precision level $\left(\alpha_{F}^{*}<\alpha_{D}^{*}<\alpha_{C}^{*}\right)$.

Proof. We are curious about the relative precision level of $\alpha_{C}$. To investigate this, we now derive the marginal gains from improving the borrower specific screening test:

$$
\begin{aligned}
\frac{\partial \pi_{\text {bank }}}{\partial \alpha_{C}} & =\frac{\partial \pi_{\text {bank }}^{D}}{\partial \alpha_{C}}+\frac{\partial \pi_{\text {bank }}^{F}}{\partial \alpha_{C}}=\frac{\partial \chi_{G}^{C}}{\partial \alpha_{C}} \frac{\partial \pi_{\text {bank }}^{D}}{\partial \chi_{G}^{C}}+\frac{\partial \chi_{G}^{C}}{\partial \alpha_{C}} \frac{\partial \pi_{\text {bank }}^{F}}{\partial \chi_{G}^{C}} \\
& =\frac{\partial \chi_{G}^{C}}{\partial \alpha_{C}} \sigma A\left(\chi_{G}^{D}\right)^{\sigma}\left(\chi_{G}^{C}\right)^{\sigma-1}+\tau_{j}^{1-\sigma} \frac{\partial \chi_{G}^{C}}{\partial \alpha_{C}} \sigma A\left(\chi_{G}^{F}\right)^{\sigma}\left(\chi_{G}^{C}\right)^{\sigma-1}
\end{aligned}
$$

where $A$ is defined as before.

Let us first suppose that $\alpha_{C}^{*} \leq \alpha_{D}^{*}$ in equilibrium. Again, from Assumption 2 that marginal costs of information acquisition are increasing, it must be true that the marginal gains from improving the borrower specific screening test is smaller than the marginal gains from improving the foreign screening test:

$$
\frac{\partial \pi_{b a n k}}{\partial \alpha_{C}^{*}} \leq \frac{\partial \pi_{b a n k}}{\partial \alpha_{D}^{*}}
$$

From equations (7) and (8) in Lemma 1, it should be also true that $\frac{\partial \chi_{G}^{* D}}{\partial \alpha_{D}^{*}} \leq \frac{\partial \chi_{G}^{* C}}{\partial \alpha_{C}^{*}}$ and $\chi_{G}^{* C} \leq \chi_{G}^{* D}$. Applying these to equations (16) and (33), after accounting for Proposition 1 that $\chi_{G}^{* F} \leq \chi_{G}^{* D}$, we have:

$$
\frac{\partial \pi_{\text {bank }}}{\partial \alpha_{C}}>\sigma A\left(\chi_{G}^{* C}\right)^{\sigma}\left(\chi_{G}^{* D}\right)^{\sigma-1}\left(\chi_{G}^{* D} / \chi_{G}^{* C}\right) \frac{\partial \chi_{G}^{* C}}{\partial \alpha_{C}^{*}} \geq \sigma A\left(\chi_{G}^{* C}\right)^{\sigma}\left(\chi_{G}^{* D}\right)^{\sigma-1} \frac{\partial \chi_{G}^{* D}}{\partial \alpha_{D}^{*}}=\frac{\partial \pi_{\text {bank }}}{\partial \alpha_{D}^{*}},
$$

which leads to a contradiction to equation (34). Therefore, $\alpha_{C}^{*}>\alpha_{D}^{*}$ must hold. We conclude that the order of the screening precision level is $\alpha_{C}^{*}>\alpha_{D}^{*}>\alpha_{F}^{*}$.

Proposition 3 The export-to-domestic sales ratio is pro-cyclical in that it decreases as $\lambda$ increases, and increases as $\lambda$ decreases via both probability effect and price effect. This is the direct consequence of the counter-cyclical relative riskiness of international transactions.

Proof. (i) probability effect: we are interested in the sign of $\frac{\partial}{\partial \ln \lambda}\left(\ln \frac{\beta_{F}}{\beta_{D}}\right)$. Since $\frac{\partial \ln \gamma}{\partial \ln \lambda}=0$ and $\beta_{j}=\gamma_{j} \chi_{j}, \frac{\partial \ln \beta_{j}}{\partial \ln \lambda}=\frac{\partial \ln \chi_{j}}{\partial \ln \lambda}$ holds, and thus it is sufficient to check the sign of $\frac{\partial}{\partial \ln \lambda}\left(\ln \frac{\chi_{F}}{\chi_{D}}\right)$. Part (ii) of Lemma 2 combined with Proposition 1 gives $\frac{\partial \ln \chi_{F}}{\partial \ln \lambda}<\frac{\partial \ln \chi_{D}}{\partial \ln \lambda}$, and hence $\frac{\partial}{\partial \ln \lambda}\left(\ln \frac{\chi_{F}}{\chi_{D}}\right)<0$. Therefore, the probability effect term moves in a pro-cyclical way. 
(ii) price effect: $\log$ of trade finance premium is therefore expressed as $\ln \frac{r^{F}\left(\varphi_{s}^{\prime}\right)}{r^{D}\left(\varphi_{s}^{\prime}\right)}=\ln \chi_{G}^{D}-\ln \chi_{G}^{F}$. Differentiating this with respect to $\ln \lambda$ gives,

$$
\frac{\partial \ln \frac{r^{F}\left(\varphi_{s}^{\prime}\right)}{r^{D}\left(\varphi_{s}^{\prime}\right)}}{\partial \ln \lambda}=-\overbrace{\frac{\partial \ln \chi_{G}^{F}}{\partial \ln \lambda}}^{I}+\overbrace{\frac{\partial \ln \chi_{G}^{D}}{\partial \ln \lambda}}^{I I} .
$$

Since $\chi_{G}^{F}<\chi_{G}^{D}$ from Proposition 1, part (i) and part (ii) of Lemma 2 delivers $I<I I<0$. Therefore, $\frac{\partial \ln \left[r^{F} / r^{D}\right]}{\partial \ln \lambda}>0$, implying a counter-cyclical trade finance premium. Since $\frac{p_{b}^{F, O A}}{p_{b}^{D, O A}}=\tau_{F} \frac{r^{F}}{r^{D}}$, the relative price of export to domestic goods is also counter-cyclical, and thus the price effect term moves in a pro-cyclical way as well when demand is elastic $(\sigma>1)$. 